\title{
Decision making in crowdfunding under risk analysis
}

\author{
Jun Chen \\ School of Information \\ Management, Wuhan \\ University \\ christina_cj@whu.edu.cn
}

\author{
Long Chen \\ Economics and \\ Management School, \\ Wuhan University \\ 303588892@qq.com
}

\author{
Chen Qian \\ School of Information \\ Management, Wuhan \\ University \\ 2689139270@qq.com
}

\author{
Ke-fan Xie \\ School of Management, \\ Wuhan University of \\ Technology \\ xkf@whu.edu.cn
}

\begin{abstract}
Crowdfunding is an emerging international financial activity often performed via internet mediated platform. With the rapid growth of this financial system, rising risks would influence participant's decision making. In this study, we examine the process of a typical crowdfunding activity, pre-ordering pledging as well as its coming risks. Based on the analysis, we combine Evolutionary Stable Strategy (ESS) and General Bass Model (GBM) to build decision-making models for pre-ordering pledging theoretically where risk factors are taken into account. Finally, evolutionary game simulation system is built to simulate the dynamic decision-making behavior in a risk changing environments. The simulation results demonstrate that the currency exchange rate give great impact on international participant's decision-making behavior in crowdfunding. Low exchange rate brings less investment decision from the investor and high exchange rate leads to overheated investment which challenges funder's diligence. Project system risk may infest the participant's decisions-making process and cause ambiguity at the end. Limitation and managerial suggestions are discussed.
\end{abstract}

\section{Introduction}

With the development of internet technology and internet finance, new firms and creative projects find a new way to raise money through an internet platforms called crowdfunding platform. It allows the funders to collect money from a great number of individuals; meanwhile the individuals can invest any creative projects presented in the crowdfunding platform. The concept of crowdfunding developed from crowdsourcing, which collects information, funds and idea resources from individuals. It allows the public participates in different programs through the internet platform. Recent years, crowdfunding has attracted investors' attention for several reasons. It not only achieves self-satisfactory for personal interests, but is also associated with production priority, project involving, future benefit and control power $[1,2]$.

It is widely believed that crowdfunding has great potency to benefit innovation [3], entrepreneurship [4], sustainability [5] and smart cities [6]. With the rapidly development of internet finance, crowdfunding plays an increasingly important role in economy. Thus, crowdfunding platforms develop rapidly and globally. In 2014, the most famous crowdfunding site, Kickstarter, has attracted 7.7 million investors all over the world to help launching 77,000 creative projects [7] Furthermore, the total number of international crowdfunding projects is also increasing every year [8]. However, potential risks arise when crowdfunding is in a rapid expansion. The participating motivations in crowdfunding have attracted many scholars' attention [9]. Decision-making process in crowdfunding has become an important research area in recent years. Transaction costs, reputation, market design [10], and geographic factors [11] are believed to be of significance on decision-making process. Various potential risks may have great influence on investor's decision-making process in crowdfunding. However, most of the recent studies for decision-making under risk analysis focused on the perspectives of laws [12] or historical cases [13] qualitatively. It is necessary to analyze the decision-making process with risk factors in crowdfunding quantitatively for the purpose of understanding to what extent risk factors influence the decision-making process and how decision makers respond to the changes in risk factors.

In this paper, we analyze the risks theoretically and develop typical analytical decision-making models for crowdfunding. An evolutionary game simulation system is built to simulate the dynamic decision-making process for crowdfunding activities in risk changing environments based on system dynamics in order to analyze the impact of risks on decision-making behavior quantitatively.

\section{Related works}

\subsection{Decision making in pledging}


In the studies of decision-making in pledging, researchers believe that pre-ordering pledging is preferred in the early period when pledging demand is smaller than its market size, or the profit-sharing is preferred [14]. Promise of long-term benefit and illustration of the project's social attributes play a crucial role in project financing [15]. In addition, Kuppuswamy and Bayus [16] pointed out supportive investors' increment is negative related to the existing investors. Although these researches tried to analyze decision makers' behavior, they mainly focused on successful investment behavior and ignored the risks that brought to crowdfunding. In crowdfunding, mass individuals make decisions with more efficient information and experience, which requires the study to consider multiple conditions.

Risk investigation is also worth noticing while success factors are studied, so that the issues could be analyzed objectively. Therefore, it would be reasonable and necessary to ask the following two questions. What is the impact of risk factors on crowdfunding activities? And how participants react according to the alteration of risk factors? This study will analyze the risk factors in crowdfunding on the base of classical theoretical model, in order to fill the gap in theoretical risk research.

\subsection{General Bass Model}

The Bass Model [17], refer as the General Bass Model (GBM), is a classical method which could be used to analysis adoption and substitution for successive generations of high-technology products [18] and new products [19]. In GBM, the parameters can be estimated, and fitting without decision variables, therefore, GBM has been widely used in empirical studies [20, 21]. Today, Bass model is still widely used in the research of innovation, technology diffusion and marketing. Kumar [22] proposed energy models to enhance knowledge and skills in the efficient transfer and management of technology for optimally allocating different types of technology feasibility Bertorri [23] introduced a network structure into the Bass Model and investigated numerically the dynamics in the case of networks with different link density. In information age, Bass Model also fits to capture the underlying mechanism of information diffusion on SNS (Social Network Site). Shen [24] figures out that the Basic Bass Model captures the underlying mechanism of topic development process of the SNS such as Twitter.

Although GBM has various advantages in the study of purchasing new products or adopting technologies, the perspective of GBM is unidirectional. It cannot provide a research path on the sale side. In order to expand the applications of GBM, other classical methods are combined with GBM. Combined with Grey theory, more effective and accurate forecast can be made [25]. Combined with simulation, the research works based on Bass Model not only focus on forecast but also has been proved effective under different contexts [26]. In the study of decision making, GBM may combine with another suitable model to analyze diffusion problem on internet.

\subsection{Evolutionary Stable Strategy}

Evolutionary Stable Strategy (ESS) is the basic concept in Evolutionary Game Theory, which was originally considered for biological evolution, but now is widely used in behavioral ecology and economics. It considers a large population of bounded rational players playing a game repeatedly through time, and players learn from the experience to improve their strategy $[27,28]$. ESS has theoretical and practical guidance in digital age. Recently, ESS was used to analyze construction safety investment [29], trust decision, adaptive selection of cryptographic protocols in WSNs (Wireless Sensor Networks), and resource allocation, etc. Shen [30] studied the dynamics of a sensor node making a trust decision that will determine whether to cooperate with others, with the purpose of disclosing this evolutionary process. Based on Evolutionary Game Theory, Arora [31] propose an adaptive security model for WSNs to select cryptographic protocols during runtime. When considering an effective way to employ D2D communications for secondary users, Cheng [33] adopted replicator dynamics in Evolutionary Game Theory to model the users' behaviors.

Compared to the classical game theory, Evolutionary Game is more suitable for studying the problem in digital age. Thus, the ESS can possibly address the mass decision making issues with less asymmetric information on the internet, such as crowdfunding. However, this theory does not offer efficient method to address the problems of decision making mutation in the game.

\section{Crowdfunding and risk analysis}

\subsection{Framework of crowdfunding}

Crowdfunding Platform (CFP) is an online site that allows funders to show projects on it for raising money. Funders provide information of the crowdfunding projects, such as business plans, photos, and videos and updated processing information when the crowdfunding application is approved by the 
platform. The backers, who are interested in the crowdfunding projects, could get the information from the CFP and decide to invest/purchase them or not. Pre-ordering pledging is a typical and preferred pledging form in crowdfunding. In pre-ordering pledging, investors receive the confirmation of products/services from funders after purchasing the project. Investors are able to evaluate the received products/services as well as share their purchase experience on crowdfunding platform, project community or SNS. If most of the purchase experiences are positive, other investors will be more likely to purchase this project. Otherwise, their desires to purchase the project will decline.

Figure 1 shows the process of pre-ordering pledging in crowdfunding. If a backer chooses to purchase or invest a project, the data will be recorded on CFP.

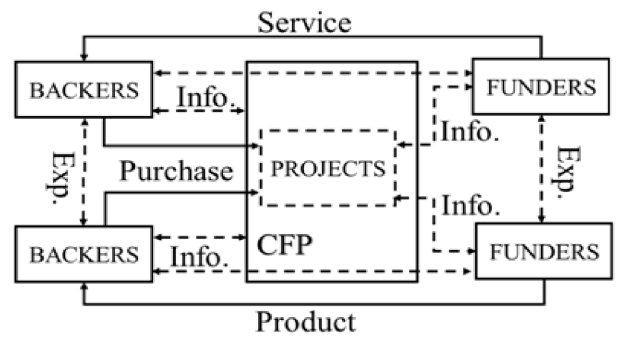

Figure 1 Process of pre-ordering pledging

$\mathrm{CFP}$ is a workplace for information transaction and data saving, which helps funders and backers to match each other. By pledging, backers gain stock share and chance to participate in program managing, such as selecting stockholder representative to guarantee the normal operation of the project and the expected dividend, and finally receive the return. However, in some non-profit projects, backer's investment could be considered as donation or charity. This case will not be discussed in this paper. In this process, backers can learn from each other's experience (Exp.), so do the funders. With CFP, both backers and funders can get more information (Info.) in the repeated crowdfunding from each side.

\subsection{Risk analysis in crowdfunding}

\section{Risk factors in crowdfunding}

Due to its special business process and mode, the rapid growth and internationalization of crowdfunding bring two major investment risks which caused by environmental factors and business factors, respectively. Most of the projects in crowdfunding are related to technology and art. Investors are relatively dispersive and have personal motivations for investment. Consequently, the risks brought by environmental factors do not bring serious threats. Compared to environmental factors, business factors bring more risks but they are are easier to be managed and recognized by carrying out risk management. CFP should effectively prevent the risks brought by business factors, or they will lead to develop restrictions and even industry recession. Generally, risks of business factors in crowdfunding are uncertainties of participants, projects and pledging process, including information security, backer's decision-making behavior, funder's credit and operating ability. Factors related to project pledging may also bring risks in investment, such as the return rate, investment threshold, and currency exchange rate when foreign backers invest the project.

\section{Risk management in crowdfunding platform}

Crowdfunding platform has taken measures to deal with the potential risk caused by business factors.

1) Risk management before pledging: Projects Selection

Before the pledging project is established, funders are required to provide real personal, credit information and valid introduction about the pledging project. CFP will verify all the applied crowdfunding projects and reject high risking projects to guarantee a high success ratio of the crowdfunding projects.

2) Risk management during pledging: financing rules. When the project is established, CFP will control the overall risk of the project by applying the financing systems. There are two systems in financing form: All or Nothing (AoN) and Keep it All (KiA).Under AoN system, money is collected from contributors if a pre-determined target has been achieved. If the goal is not met, no money is collected. In KiA, all of the money is collected without return regardless of the pledging goal is achieved or not [33].

3) Risk management after pledging: information disclosure

If a project has pledged enough money, funders are required to update the project's latest information and post the information in the most conspicuous places to capture backers' attention. Funders can also pass the latest information, texts, pictures and video clips to the backers on his SNS, in the project's community or by other interaction channels.

\section{Decision-making model for crowdfunding}

In crowdfunding, backers and funders make 
decisions as a repeated game. Individual decision maker interact and exchange information with each other through SNS, CFP and other interaction assisted tools. He or she learns from others' experiences again and again to form his or her own decisions. Backers make decisions with the help of experience learned from feedback. Funders can also notice the reaction of backers when feedback is received by the backers. More details of decision-making process will be considered in the typical crowdfunding game model.

\subsection{Combination of ESS and GBM}

In the pledging game process, what we are facing is a multi-objective decision-making problem. Both funders and backers have to be considered together and each side's decision-making is affected by the other side.

GBM can be used to analyze internet related problem with the condition of mass decision making. Thus, it is suitable for modeling the group decision making behaviors. However, as discussed, the perspective of GBM is unidirectional; it cannot provide a research path on the funder side in the process of crowdfunding. It cannot be used to analyze the related influence between two decision-making groups (bakers and funders) in crowdfunding. As we mentioned above, the decision-making process in crowdfunding is regarded as a game. Compared to other approaches, ESS takes a large population of bounded rational players into consideration, which just meet our requirements and is a suitable strategy to provide solutions for multi-objective decision-making problem in game. Therefore, we consider using GBM to build the multi-objective group decision-making model and applying an evolution based game ESS to improve the decision-making model as well.

Based on GBM, we argue that the general equation for describing the process of adopting new products in population could also model the per-ordering decision making behavior for purchasing new products or services in crowdfunding.

$$
\frac{f(t)}{1-F(t)}=p+q F(t)
$$

Where $f(t)$ is the rate for change of the purchase penetration, $F(t)$ is the purchase penetration, $p$ is the coefficient of innovation and $q$ is the coefficient of imitation.

Then we introduce an evolutionary based game, ESS. In this game, there are two strategies $S 1$ and $S 2$ for backer. $S 1$ denotes "purchase" and $S 2$ denotes "not purchase", $x$ is the proportion to choose purchase with mass backers. Similarly, $y$ is the proportion to choose the first strategy for funders in a mass. Refer to the replicator dynamic [34] as the strategy reply in ESS, the replicator dynamic equation for backers is:

$$
\frac{d x}{d t}=x\left(E_{1}-\bar{E}\right)=x(1-x)\left(u_{1}-u_{2}\right)
$$

Where $t$ is the time, $u_{1}$ is the revenue of $S 1, u_{2}$ is the revenue of $S 2, x$ is the proportion of backers who choose purchase (S1), $E_{1}$ is the expected revenue of $S 1, \bar{E}$ is the average expected revenue of the population. Based on the above discussion, we notice that $x$ and $F(t)$ have the similar meaning. Set $x=F(t)$, the replicator dynamic can be expressed as:

$$
F^{\prime}(t)=f(t)=\frac{d x}{d t}=F(t)[1-F(t)]\left(u_{1}-u_{2}\right)
$$

From equation (1), the rate of change of the purchase penetration be expressed as:

$$
\begin{aligned}
& f(t)=F(t)[1-F(t)] q+[1-F(t)] p \\
& \text { If }\left(u_{1}-u_{2}\right)=q, \text { equation (3) and equation }
\end{aligned}
$$

would have the same expression form. In the GBM, $q$ is the coefficient of imitation in GBM which represents external factors for purchasing a new product. Moreover, $\left(u_{1}-u_{2}\right)$ is the extra revenue of purchasing which also represents one kind of external factors. Theoretically, replicator dynamic can be explained as the external influence of purchasing decision in the GBM when revenue is the only external factor considered. In other words, the replicator dynamic expresses the imitation of decision makers who learn from experience revenue receiving, and the extra revenue expands the changing ratio in decision-making.

Both GBM and ESS have drawbacks. The replicator dynamic has shown the imitative rule for bounded rational decision makers with experience, probably, rational enough for mass backers or funders. As the bounded rational hypothesis is limited, we will consider the irrational decision for improvement. The replicator dynamic needs to be expanded with another decision-making relationship which does not consider the revenue as the mutation in the game.

In economics, the decision making without profit consideration is regarded as irrational. In equation (4), $p$ is the coefficient of innovation which denotes internal factors. The innovative purchase was motivated by individual reasons (internal factors) only. Without major consideration of profit, $p$ represents irrational factors. It is noticed that the other part of equation (4), $[1-F(t)] p$, represents the irrational factors influence on purchase decision making in economic perspective.

As the game is dynamic, the coefficient of irrationally decision-making should not be fixed as the 
setting in GBM, but changing with the strategy proportion which refers to Evolutionary Theory. Setting the relation of irrationally decision-making and the proportion of $S_{1}$ is $p P(F(t))$, where $p$ is the risk variable from individuals which shows the uncertain of irrationally decision-making. $P(F(t))$ is the relation function of $F(t)$ and $p . p P(F(t))$ represents the mutation of strategy choice which does not be considered in the replicator dynamic equation (2) or (3). In this paper, $p$ is negatively correlated with the decision consistency, that is, if the decision makers almost choose the same strategy, irrationally decision-making behavior will decrease and everyone's choice is more profitable. Based on the above discussion, relation function can be set as:

$$
P(F(t))=1-|1-2 F(t)|
$$

Combine equations (3), (4) and (5), the rate of the purchase penetration changes where both rational and irrational decisions are considered in a repeated game is presented as:

$$
f(t)=F(t)[1-F(t)]\left(\mathrm{u}_{1}-u_{2}\right)+[1-F(t)] p P(F(t))
$$

Substitute equation (5) into (6), we have:

$$
f(t)=F(t)[1-F(t)]\left(\mathrm{u}_{1}-u_{2}\right)+[1-F(t)] p(1-|1-2 F(t)|)
$$

Equation (7) shows a general expression form for mass decision-making which take both rational and irrational decisions into consideration in a repeated game. It is a general discrete decision-making model in crowdfunding. It will be used for pre-ordering game modeling later.

\subsection{Decision-making modeling for pre-ordering pledging}

\section{Assumptions and parameters used for modeling}

Before building the decision-making model for pre-ordering pledging, we have the following assumptions.

1) Decision makers are bounded rational.

2) $f(t)$ presented in equation (6) is used to model the decision-making changes.

3) For clarity of comparison, all the returns are calculated as NPV.

4) Information is efficient

We assume there is infinity of potential backers (investors or purchasers). Crowdfunding projects are open to international investment. Backers use domestic currency $D C$ to invest/purchase the project. Crowdfunding projects use foreign currency $F C$ as the settlement currency.

Definition 4.1: Let $S_{B} \in\left\{S_{B 1}, S_{B 2}\right\}$ be the backer's investment strategy $S_{B 1}$ denotes backer's choice of investing the project and $S_{B 2}$ denotes backer's choice of not investing the project. The probability of each choice is denoted by $b_{1}$ and $b_{2}$ respectively, $b_{1}+b_{2}=1$.

Definition 4.2: Let $x$ be the ratio of backer who accept the creative project or investment choice. $x$ reflects backer's investment decision in crowdfunding.

Definition 4.3: Let $S_{F} \in\left\{S_{F 1}, S_{F 2}\right\}$ be the funder's service strategy. $S_{F 1}$ denotes high cost and high return are promised by the funder and $S_{F 2}$ denotes low cost and low return. The probabilities of each strategy is denoted by $a_{1}$ and $a_{2}, a_{1}+a_{2}=1$.

Definition 4.4: Let $y$ be the ratio of hard-working funders. $y$ reflects funder's return decision in crowdfunding.

Given a crowdfunding project, with $m$ potential backers, the average investment from backers is $C_{0}$, the pre-determined target is set to $w^{\prime}$, and $t_{0}$ denotes the time used for pledging, $w$ denotes the actual amount of capital be raised. The actual pledged capital is calculated for the two financing systems separately.

In $\mathrm{KiA}$ system

$$
w=x_{t_{0}} m C_{0}
$$

In AoN system

$$
w=\left\{\begin{array}{c}
x_{t_{0}} m C_{0}, x_{t_{0}} m C_{0} \geq w^{\prime} \\
0, x_{t_{0}} m C_{0}<w^{\prime}
\end{array}\right.
$$

In pre-ordering pledging modeling, four major risk factors will be taken into consideration in decision-making process. They are irrational decision-making risk from both backers $p_{x}$ and funders $p_{\mathrm{y}}$, currency exchange rate $e$ and pledging system risk $\pi$.

Definition 4.5: Let $e_{t}$ be the currency exchange rate at $t, e_{t}=F C / D C . \delta_{t}$ is the change of $e_{t}$ at time $t, e_{0}$ is the initial rate, $e_{t}=e_{0}+\sum_{0}^{t} \delta_{t}$.

\section{Pre-ordering Game modeling}

This study chooses Kickstarter's working mode to launch decision-making modeling. As the most famous pre-ordering crowdfunding platform, Kickstarter established in U.S. and it is the largest synthesized crowdfunding platform. In 2014, 3.3 million people that all over the world has pledged more than half a billion dollars (that's $\$ 1,000$ in every minute) to support 22,252 creative projects. Backers are welcome to invest their preferred programs via the platform, but only U.S. 
dollars or GB pounds are accepted as the settlement currency. Therefore, foreign currency exchange rate may bring risk to the investment of crowdfunding.

Kickstarter adopts the financing mechanism of AoN. Funders need to establish a pre-determined target and a deadline for the pledging. The raised capital will be refunded if the target cannot be achieved in time. Commonly, Kickstarter charge $5 \%$ of the fund and Amazon, the capital operating partner, would collect another $3-5 \%$. The pledging project will be recorded online for reference.

As to the modeling of pre-ordering, participants in Kickstarter are completely in conformity with the characteristics of repeated gaming. In addition, database and credit system established by project recording, provide references for decision makers to learn from.

This part proposes a pre-ordering game to analyze the impact of risks on decision-making. For the pre-ordering funders, if the collected capital reaches the pre-determined target $w^{\prime}$, the funder will get enough money to reach the most efficiency level and provide high quality or return $\left(R^{H}\right)$ with the minimum cost $C_{\text {min }}$. If the collected capital does not reach $w^{\prime}$, the funder will choose to offer high return $\left(R^{H}\right)$ with high $\operatorname{cost}\left(C^{H}\right)$ or low return $\left(R^{L}\right)$ with low $\operatorname{cost}\left(C^{L}\right) \cdot \pi$ denotes the project operation risk factor. In this study, it is the posterior probability of reaching the efficiency level in pre-ordering pledging.

$$
\begin{gathered}
C^{H}>C^{L}>C_{\text {min }} \\
R^{H}>R^{L}
\end{gathered}
$$

Considering the probability and the process of a similar lemons problem in crowdfunding, ESS would change with the time delay in discrete replicator dynamics. It implies that the probability of choosing strategy $S_{F 2}$ will increase with time and the expected revenue for backers will be reduced, and then the purchase penetration will be reduced accordingly. Finally, total revenue for funders is reduced. So that when the funders choose $S F_{1}$, the purchase penetration is $F_{x}(t-1)$, and if the funders choose $S_{F 2}$, the purchase penetration is $F_{x}(t)$. It is approximated in the discrete analogue of the GBM, in this model, time delay is accurate. Before the game, funders will give the pre-ordering price $C_{0}$ in currency $\mathrm{FC}$ and the confirmatory is returned. Backers do not know the probability of strategies chosen by funders. In each round, backers and funders make decisions from past experiences and revealed information. We use equation (6) to model decision-making changes. The Sequence of events occurred in the game is presented as follows:

1) Backers make their decisions.

2) Projects start to raise capital on the crowdfunding platform.

3) When pledging is accomplished, funders operate the project and make the return decision.

4) Backers receive the return, share the experiences, and go back to step 1).

Using AoN financing mechanism, projects get the pledged capital successfully when $w \geq w^{\prime}$.We assume that successful crowdfunding projects are more likely to reach the efficiency level in AoN, consider as $\pi \rightarrow 1$. The game tree and the revenue are shown in Figure 2.

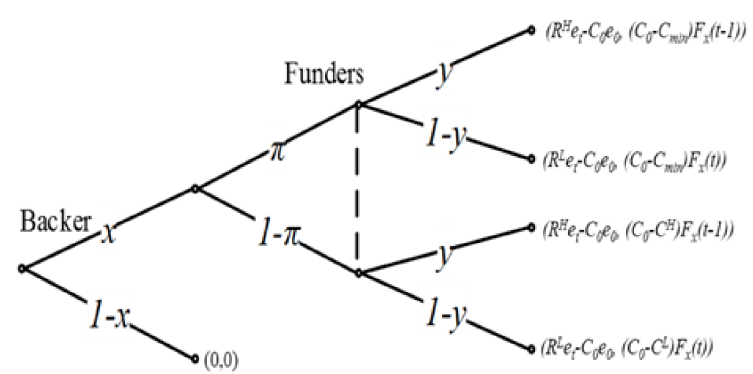

Figure 2 Pre-ordering game tree and the revenue

In pre-ordering game,

$$
\begin{array}{r}
f_{x}(t)=F_{x}(t)\left[1-F_{x}(t)\right]\left(y e_{t}\left(R^{H}-R^{L}\right)+R^{L} e_{t}-C_{0} e_{0}\right) \\
+\left[1-F_{x}(t)\right] p_{x} P_{x}\left(F_{x}(t)\right)
\end{array}
$$

Let $f_{x}(t)=0$, here is $F_{x}(t)=1,0$ or

$$
\begin{gathered}
y=\frac{C_{0} e_{0}-R^{L} e_{t}}{e_{t}\left(R^{H}-R^{L}\right)}-\frac{p_{x} P_{x}\left(F_{x}(t)\right)}{F_{x}(t) e_{t}\left(R^{H}-R^{L}\right)} \\
f_{y}(t)=F_{y}(t)\left[1-F_{y}(t)\right]\left\{\begin{array}{r}
\left(C_{0}-\pi C_{\min }\right) x m\left[F_{x}(t-1)-F_{x}(t)\right] \\
+(\pi-1) x m\left[C^{H} F_{x}(t-1)-C^{L} F_{x}(t)\right]
\end{array}\right\} \\
+\left[1-F_{y}(t)\right] p_{y} P_{y}\left(F_{y}(t)\right)
\end{gathered}
$$

Let $f_{y}(t)=0$, here is $F_{y}(t)=1,0$ or

$$
x=\frac{-p_{y} P_{y}\left(F_{y}(t)\right)}{\left(C_{0}-\pi C_{\min }\right) m\left[F_{x}(t-1)-F_{x}(t)\right] F_{y}(t)}
$$

\section{Simulation and results analysis}

Analytical solution of pre-ordering game implies that the correlations among ESS, returns and risk factors are extremely complex. Therefore, we propose a 
numerical case simulation and test the impact of risk factors on decision-making process in pre-ordering game in the following.

\subsection{Simulation model and parameter setting}

Based on the system dynamics [35], this paper builds evolutionary game simulation system to simulate the dynamic decision-making in a risk changing environments.

Table 1 System parameter settings

\begin{tabular}{|c|c|c|}
\hline Parameters & Settings & Descriptions \\
\hline e & Initial value 5 & Currency exchange rate \\
\hline $\mathrm{x}$ & $\begin{array}{l}\text { Initial value } \\
0.5\end{array}$ & $\begin{array}{l}\text { Ratio of backers who } \\
\text { purchase projects }\end{array}$ \\
\hline $\mathrm{y}$ & $\begin{array}{l}\text { Initial value } \\
\quad 0.5 \\
\end{array}$ & $\begin{array}{l}\text { Ratio of hard-working } \\
\text { funders }\end{array}$ \\
\hline $\mathrm{C} 0$ & 10 & Pre-ordering price \\
\hline Cmin & $0.5^{*} \mathrm{C} 0$ & Minimum cost \\
\hline $\mathrm{RH}$ & Cmin*2.15 & High return \\
\hline $\mathrm{CL}$ & Cmin*1.5 & Low cost \\
\hline $\mathrm{RL}$ & Cmin*1.8 & Low return \\
\hline delta e & $\begin{array}{l}\text { e*RANDOM } \\
\text { UNIFORM(-0 } \\
.05,0.05,0.001) \\
\end{array}$ & Changes of exchange rate \\
\hline fx & $\begin{array}{c}\text { Follows } \\
\text { equation (10), }\end{array}$ & $\begin{array}{l}\text { Rate of the "purchase" } \\
\text { penetration changes from } \\
\text { backers }\end{array}$ \\
\hline fy & $\begin{array}{c}\text { Follows } \\
\text { equation (12) }\end{array}$ & $\begin{array}{l}\text { Rate of the "hard working" } \\
\text { penetration changes from } \\
\text { funders }\end{array}$ \\
\hline $\mathrm{pxP}(\mathrm{x})$ & $\begin{array}{c}\text { RANDOM } \\
\text { NORMAL(-0. } \\
01,0.01,0,0.003, \\
0.005) *(1-A B S( \\
1-2 * x))\end{array}$ & $\begin{array}{c}\text { Influence of irrational } \\
\text { decision risk from backers }\end{array}$ \\
\hline pyP(y) & $\begin{array}{c}\text { RANDOM } \\
\text { NORMAL }(-0 . \\
01,0.01,0,0.003, \\
0.003) *(1-A B S \\
(1-2 * \mathrm{y})) \\
\end{array}$ & $\begin{array}{l}\text { Influence of irrational } \\
\text { decision risk from funders }\end{array}$ \\
\hline pi & $0.95 * \mathrm{x}$ & System risk factor \\
\hline
\end{tabular}

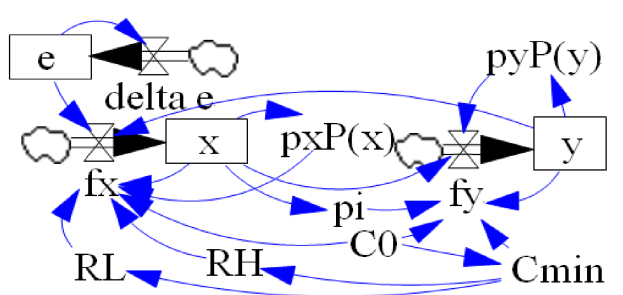

Figure 3 Pre-ordering game simulation system

In the pre-ordering game simulation system as shown in Figure 3, the arrow denotes one factor influences another one. $x$ and $y$ in the box denote game strategy probability of both sides in pledging game which are represented by rate variable. $f_{x}$ and $f_{y}$ denote the speed of change in both sides' group strategy probability, which represented by flow rate, that is, the changes in every decision cycle. $e$ in the box denotes the exchange rate represented by rate variable, which is cumulative increasing or declining during a changing trend. $\mathrm{C}_{0}$ denotes purchase price, and it is a constant. According to the process in the game tree and its equation, we can see that every factor gives impact on $f_{x}$ and $f_{y}$.

Parameter setting of the simulation system is summarized in Table 1. The values of parameters are set according to the average level of a real normal market. The initial decision making proportion is set to 0.5 for both backers and funders. This represents a typical normal game state. Players choose strategies randomly, because none of them has efficient information or experience to support their decisions. Particularly, the irrational decision-making risk factors are also set as random. The format in parameter settings follows the coding rules of system dynamics simulation software, Vensim 5.0. RANDOM NORMAL (Min Max Mean Stdev. Seed) sets the immeasurable risk factor to be subject to normal distribution with the conditions of minimum, maximum, mean value, standard deviation and initial vale. Thus, the numerical case simulation can be tested with dynamic and uncertain risk factors.

\subsection{Simulation results}

In this section, the simulation results are presented to analyze the impact of risk factors on decision-making in pre-ordering pledging.

Table 2 Influence degree of risk factors

\begin{tabular}{ccccc}
\hline $\begin{array}{c}\text { Risk } \\
\text { factors }\end{array}$ & Parameters & $\begin{array}{c}\text { Parameter } \\
\text { variation } \\
\text { method }\end{array}$ & $\begin{array}{c}\text { Backer's } \\
\text { Decision(x) }\end{array}$ & $\begin{array}{c}\text { Funder's } \\
\text { Decision(y) }\end{array}$ \\
\hline $\begin{array}{c}\text { Irrational } \\
\text { decision }\end{array}$ & $p_{x}$ & Exp & $\mathrm{NS}$ & $\mathrm{N}$ \\
$\begin{array}{c}\text { Exchange } \\
\text { rate }\end{array}$ & $e$ & $\mathrm{Exp}$ & $\mathrm{N}$ & $\mathrm{NS}$ \\
$\begin{array}{c}\text { System } \\
\text { risk }\end{array}$ & $\pi$ & Raise & $\mathrm{P}$ & $\mathrm{N}$ \\
\hline
\end{tabular}

To capture the influence of risk factors on decision-making, we apply different variation methods to their corresponding parameters, such as at random range, different expectations, risk uncertainties and degrees. We use six levels to measure the influence degree of the four major risk factors. They are Completely change(C), Extremely Negative effect (EN), Negative effect(N), No Significant effect(NS),Positive impact(P), Extremely Positive impact(EP). The 
influence degree of each risk factor is shown in Table 2. The results imply that backer's irrational decision gives negative effect on funder's decision and vice versa. When currency exchange rate rises, backers are more likely to make investment decisions and funder's intention to offer high return is weak. However, when currency exchange rate goes down, backers completely change their investment decisions and funders are more willing to work hard and provide good services. When system risk uncertainty increases, both backer and funder completely change their decisions.

Besides showing the influence degree of each risk factor on decision making, we further analyze the backer's decision-making trend when risk factor is in a changing situation. In the following figures, horizontal axis denotes the time and the vertical axis denotes the strategy penetration of backers and funders. With standardization, the value of strategy penetration is controlled and ranges from 0 to 1.1 means that all the backers choose to purchase or investment (or all the funders choose to work hard or offer high return), otherwise, 0 means that no one chooses to take part in Crowdfunding. In Figure 4-5, Blue curve denotes the decision of backer and red one denotes the decision of funder.

Figure 4 shows backer and funder's decisions under bearish currency exchange rate. With bearish currency exchange rate, there is a rapid decline on backer's decision of investing project though the funders choose high level of effort and provide good services and high return. In this situation, crowdfunding will go to the winter period, because no more backers want to invest the project. There is one way to break this impasse. Funders need to keep on providing high service quality and return to backers. After a period of time, the probability of backers' investment decision will gradually increase.

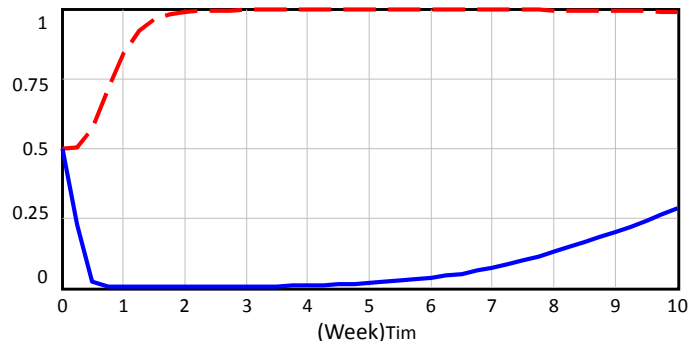

$\overline{-----------1}$

Figure 4 Decisions under bearish currency exchange rate

Figure 5 shows backer and funder's decisions under bullish currency exchange rate. With bullish currency exchange rate, backers' decision on investing project increases. Compared to the situation of stable exchange rate, backers prefer to make investing decisions. Meanwhile, due to large amount of backers' support, funders can choose to make less effort to maintain the sustained crowdfunding. However, this is not the most efficient result in crowdfunding activities. When currency exchange rate becomes bullish, funders can make less effort, but this is not the result of a virtuous circle. Figure 5 implies that funders may not always offer high return in the game.

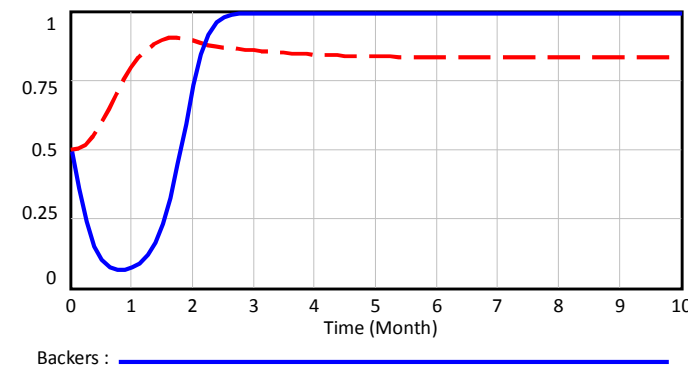

Figure 5 Decisions under bullish currency exchange rate

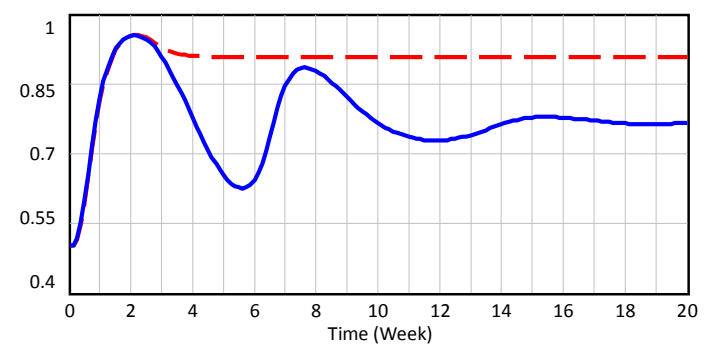

Funders: Curve 1

Funders: Curve

Figure6 Backer's decision under different financing mechanisms

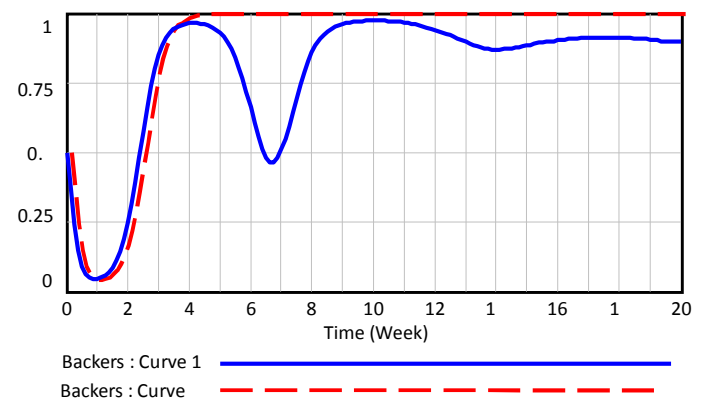

Figure 7 Funder's decision under financing mechanisms

Figure 6 shows backer's decision under the different financing mechanisms and Figure 7 shows funder's decision under different financing mechanisms. The blue curve denotes backer/funder's decision under $\mathrm{KiA}$ mechanism and red one denotes backer/funder's 
decision under AoN mechanism.

Let $\pi \rightarrow 1$ in the AoN mechanism and $\pi \rightarrow 0.7$ in the KiA mechanism. When $\pi$ decreases from 1 to 0.7 , it implies the financing mechanism is changed from AoN to KiA. Different mechanism corresponds to different pledging system risk level. This change increases the system risk of crowdfunding platform. Thus, decision-making process of the participants becomes unpredictable and out of control. Finally, the game may change repeatedly and take a long time to reach the ESS. Raising the success probability of pre-ordering projects may help to offer a low risk investment environment in crowdfunding platform. Therefore, more backers will participate in the project, and successful experience in crowdfunding will be improved.

\section{Discussion and conclusion}

\subsection{Key findings}

As an essential part of internet finance, crowdfunding plays an increasingly important role in today's economy. The success of crowdfunding depends on participants' decisions. This paper combines two classical theories to build decision-making models for pre-ordering pledging, where risk factors are taken into account. An evolutionary game simulation system is built to simulate participants' dynamic decision-making behaviors in a risk changing environments. Finally, the influence of risk factors on participants' decision making behaviors is analyzed quantitatively in crowdfunding. The observations are summarized below:

1) With the internationalization of crowdfunding, foreign backers are suffering from the risk caused by fluctuation in currency exchange rate. When exchange rate drops, investment decisions made by foreign backers decline tremendously. In this situation, foreign backers are not likely to invest the project on the crowdfunding platform. Without enough participants, the whole crowdfunding system becomes hard to operate. While a rise of exchange rate will lead to overheated investment, which is caused by the Herd Effect. This may further challenge funders' diligence.

2) Increasing the project system risk may lead participants' decisions into the process of repeated mutual testing and cause ambiguity at the end. A stable decision-making process can be achieved if only an equilibrium strategy can be found between funders and backers in the long-term of repeating game. The evolutionary stable strategies from both sides determine the final developmental level of the decision-making process.

\subsection{Managerial suggestions}

The findings of this study also provide useful guidance to the crowdfunding platform operator/manager who plans to control the risks and develop better pre-ordering pledging activities. The managerial suggestions for practices are as follows:

1) Try to spread financial risks, encourage international backers' participation as well as promoting internationalization development of crowdfunding activities. At the same time, crowdfunding platform operators need to establish efficient incentive system and more strict rules to help avoid funders' lazy action, which is caused by exchange rate raise and pre-ordering backers' overheated investment.

2) Try to control the project system risk by applying technological means and risk assessment. Guarantee a favorable investment environment, an honest atmosphere and a positive growing trend.

\subsection{Limitations}

This paper has several limitations. We only analyze the decision-making process of pre-ordering activity and take four risk factors into account. Another crowdfunding activity referring to equity pledging should be considered in future works. The analysis of mass decision making process is this paper has ignored the individual characteristics of crowdfunding projects and participants. Multi-agent simulation may be suitable to address these issues. In addition, empirical analysis needs to be taken into account for theoretical verification.

\section{Acknowledgement}

This research is supported by National Social Science Foundation of China (16ZDA039) and scholars academic development program, "big data and business analysis" academic team, Wuhan University.

\section{Reference}

[1] Schwienbacher A, and Larralde B, "Crowdfunding of small entrepreneurial ventures", SSRN Electronic Journal.SSRN. doi: 10.2139/ssrn.1699183, 2010.

[2]Ordanini A, Miceli L, and Pizzetti M, et al., "Crowdfunding: transforming customers into investors through innovative service platforms", Journal of Service Management, 22(4) , 2011, pp.443-470. 
[3]Colombo M G, Franzoni C, and Rossi-Lamastra C, "Internal social capital and the attraction of early contributions in crowdfunding", Entrepreneurship Theory and Practice, 39(1) , 2015, pp. 75-100.

[4]Caudoux, A., and J. Geoffroy, "Financing solutions to sustain the growth of SMEs and MTEs and lay the foundations for future competitiveness", Financial Stability Review, (19), 2015, pp.37-49.

[5]Funk A S., "Institutions Influencing the evolution of crowdfunding in China: A Review of the World Bank Report on Crowdfunding's Potential for the Developing World", Crowdfunding in Europe, Springer International Publishing, 2016, pp.125-131.

[6]Medda F R, Partridge C, and Carbonaro G, "Energy investment in smart cities unlocking financial instruments in Europe", Handbook of Research on Social, Economic, and Environmental Sustainability in the Development of Smart Cities, 2015, pp.408-433.

[7]Al Sohibani M, Al Osaimi N, and Al Ehaidib R, et al.,"Factors that influence the quality of crowdsourcing", New Trends in Database and Information Systems II, Springer International Publishing, 2015, pp.287-300.

[8]Ward C, and Ramachandran V,"Crowdfunding the next hit: Microfunding online experience goods" Proceedings of, Workshop on Computational Social Science and the Wisdom of Crowds at NIPS2010, 2010, pp.1-5.

[9]Gerber E M, and Hui J, "Crowdfunding: Motivations and deterrents for participation", ACM Transactions on Computer-Human Interaction (TOCHI) 20(6), 2013, pp.34

[10]Agrawal, A., Catalini, C., and Goldfarb, A. "Some simple economics of crowdfunding", Innovation Policy and the Economy, 14(1), 2014, pp.63-97.

[11]Mollick E, "The dynamics of crowdfunding: An exploratory study", Journal of Business Venturing, 29(1), 2014, pp.1-16.

[12]Bradford C S.,"Crowdfunding and the federal securities laws", Columbia Business Law Review, (1),2012, pp.1-150.

[13] Harrison R, "Crowdfunding and the revitalisation of the early stage risk capital market: Catalyst or chimera?", Venture Capital, 15(4), 2013, pp. 283-287.

[14]Belleflamme P, Lambert T, and Schwienbacher A, "Crowdfunding: Tapping the right crowd", Journal of Business Venturing, 29(5), 2014, pp. 585-609.

[15]Ethan R M.,"The Dynamics of crowdfunding: Determinants of success and failure", Journal of Business Venturing, 29(1), 2014.

[16]Kuppuswamy V, and Bayus B L, "Crowdfunding creative ideas: The dynamics of project backers in Kickstarter", UNC Kenan-Flagler Research Paper, 2015.

[17]Bass F M, "Comments on 'a new product growth for model consumer durables the bass model", Management Science, 50(12), 2004, pp. 1833-1840.

[18]Norton J A, and Bass F M., "A diffusion theory model of adoption and substitution for successive generations of high-technology products", Management Science, 33(9), 1987, pp. 1069-1086.

[19]Mahajan V, Muller E, and Bass F M, "New product diffusion models in marketing: A review and directions for research", The Journal of Marketing, 54(1)1990, pp.1-26.

[20]Mahajan V, and Muller E, "Timing, diffusion, and substitution of successive generations of technological innovations: The IBM mainframe case", Technological Forecasting and Social Change, 51(2), 1996, pp.109-132.

[21]Lee J, Cho Y, and Lee J D, et al., "Forecasting future demand for large-screen television sets using conjoint analysis with diffusion model", Technological Forecasting and Social Change, 73(4), 2006, pp.362-376.

[22]Kumar R, and Agarwala A,"Renewable energy technology diffusion model for techno-economics feasibility", Renewable and Sustainable Energy Reviews, 54, 2016, pp.1515-1524.

[23]Bertotti M L, Brunner J, and Modanese G,“ The Bass diffusion model on networks with correlations and inhomogeneous advertising", Chaos, Solitons \& Fractals, 90, 2016, pp. 55-63.

[24]Shen Y, "Forecasting Twitter topic popularity using bass diffusion model and machine learning”, Massachusetts Institute of Technology, 2015.

[25]Abu N, and Ismail Z, "Forecasting sales of new vehicle with limited data using Bass diffusion model and Grey theory", Proceedings of the 2nd International Statistical Conference 2014 (ISM-II): Empowering the Applications of Statistical and Mathematical Sciences. AIP Publishing, 1643 (1), 2015, pp. 467-475.

[26]Yang G Z, and Yan Z, "A contingent technology innovation diffusion model and simulation”, Proceedings of international Conference on Management Science and Management Innovation (MSMI 2015), 2015, pp. 310-315.

[27]Smith J M., and Price G R., "The logic of animal conflict”, Nature, 246(5427), 1973, pp. 15-18.

[28]Taylor P D, and Jonker L B, "Evolutionary stable strategies and game dynamics", Mathematical Biosciences, 40(1), 1978, pp. 145-156.

[29]Wang W, Yang Q, and Lu M, et al., "Research on the construction safety investment regulation evolutionary game and application", Proceedings of the $8^{\text {th }}$ International Conference on Management Science and Engineering Management. Springer Berlin Heidelberg, 2014, pp. 145-153. [30]Shen S, Jiang C, and Jiang H, et al, "Evolutionary game based dynamics of trust decision in WSNs", Sensor Network Security Technology and Privacy Communication System (SNS \& PCS), Proceedings of the 2013 International Conference on. IEEE, 2013, pp. 1-4.

[31]Arora S, Singh P, and Gupta A J, "Adaptive selection of cryptographic protocols in wireless sensor networks using evolutionary game theory”, Procedia Computer Science, 78, 2016, pp. 358-366.

[32]Cheng P, Deng L, and $\mathrm{Yu} \mathrm{H}$, et al, "Resource allocation for cognitive networks with D2D communication: An evolutionary approach", Proceedings of the Wireless Communications and Networking Conference (WCNC), 2012 IEEE, 2012, pp. 2671-2676.

[33]Ashton A J, Russo P, and Heenatigala T, "Crowdfunding astronomy outreach projects: Lessons learned from the UNAWE crowdfunding campaign", Communicating Astronomy with the Public Journal,16, 2014,pp.24-27.

[34]Hofbauer J, and Sigmund K, "Evolutionary games and population dynamics", Cambridge University Press, 1998.

[35]Barlas Y, "Formal aspects of model validity and validation in system dynamics", System Dynamics Review, 12(3), 1996, pp.183-210. 